\title{
Dysmenorrhoea and absenteeism in school girls
}

Premalatha Balasuriya'

The Ceylon Journal of Medical Science 1997; 40: 01-06

\section{Summary}

The prevalence of dysmenorrhoea and the resulting disability and absenteeism were studied in school girls. The subjects comprised 345 girls from 2 girls' schools and 187 girls from 2 co-educational schools in Kandy. General information and a detailed menstrual history with special emphasis on dysmenorrhoea, disability and absenteeism were obtained by means of a questionnaire. An educational programme on the significance of menstruation and simple ways of coping with dysmenorrhoea was conducted to subjects of one girls' school and one co-educational school. These were considered as the study groups while the other 2 schools were considered as the control groups. A repeat questionnaire was given to both groups 6 months later, to obtain details about the last menstrual periods. Analysis of data showed the following: A significantly higher percentage of subjects from girls' schools belonged to higher social classes $(p<0.001)$, while a significantly higher percentage from co-educational schools resorted to traditional beliefs $(p<0.05$ and $<0.001$ ); the degree and prevalence of pain and disability were not significantly different between any two schools ( $p<0.05$ ); absenteeism from school due to dysmenorrhoea was significantly higher in co-educational schools $(p<0.001)$; there was an increase in the degree and prevalence of pain and disability with age. Six months later, a significant decrease $(p<0.05)$ in absenteeism was observed in the study groups, while the other variables remained unchanged in both groups.

The study indicates that social class or coeducation do not significantly affect the degree of dysmenorrhoea and the resulting disability in school girls, but may affect school attendance which could be improved by educational programmes.

\section{Introduction}

Primary dysmenorrhoea is a common disorder occurring in young women. It is reported to be the commonest of all gynaecological disorders and the commonest cause of lost work hours/school hours among women $(1,2)$. The prevalence of dysmenorrhoea as reported for different populations vary considerably due to variabilities in criteria employed.

The prevalence rates for American adolescents in 2 recent studies were observed to be $79.6 \%$ and $91 \%$ with $18 \%$ and $23 \%$ respectively being severely affected $(3,4)$. A prevalence of $72 \%$ has been reported for 19 year old Swedish girls (5) with an absenteeism from work or school of $51 \%$ and a mean degree of severity of dysmenorrhoea determined on a linear analogue scale of 4.1 (SD 3.2). The prevalence increases from $39 \%$ at 12 years to $72 \%$ at 17 years in American girls (6). No significant differences in school attendance or examination results were observed between British girls with dysmenorrhoea and matching controls (7).

The incidence is affected by social status, occupation, age and environmental factors. Psychogenic factors, lack of knowledge about the significance of menstrual function, overanxious mothers, misconceived ideas and beliefs, traditions, fear and anxiety and experience of dysmenorrhoea in family members accentuate the subjective pain element so that girls are led to believe that menstruation is an unwell period. Education on the significance of menstruation, general health and regular physical activity, together with reassurance have been implicated as having beneficial effects on dysmenorrhoea $(1,4,8)$.

Data on the prevalence of dysmenorrhoea or the incapacity and absenteeism due to 
dysmenorrhoea in developing countries are very limited. For Sri Lanka, the prevalence rate documented by an Ayurvedic practitioner is $70 \%$, with a severe incapacity in $5 \%(9)$. In an earlier study, we reported the prevalence of dysmenorrhoea in 117 first year medical students to be $70 \%$ with a mean degree of pain of 5.5 and SD of 2.7 as determined on a linear analogue scale (10). In this study, $50 \%$ reported inability to carry out normal daily work for a varying period with a mean of 5.2 hours and a SD of 5.8.

The objectives of the present study were to determine the following in 2 groups of school girls in Kandy: the degree and prevalence of dysmenorrhoea; the degree of disability, prevalence of disability and absenteeism from school or classes due to the disability; the effect of age, social class and co-education on the above factors; the effect of an educational programme on the above factors; relationship of the degree of dysmenorrhoea to the age at menarche, degree of bleeding, cycle length and academic performance; and traditional beliefs regarding menstruation.

\section{Subjects and Methods}

Two groups of schools were selected on a random basis, in and around the Kandy city. Group A comprised two leading girls' schools from the city subdivided into A1 and A2. Group $B$ comprised two co-educational schools outside the city subdivided into B1 and B2. In Group B schools, all the girls in and above School Year 9 were used for the study giving a total of 187 subjects, while in Group A schools, 1 to 2 classes from each School Year were used on a random basis giving a total of 345 subjects. This was done as the total number of girls in Group B schools was small. The age range of the subjects in Year 9 was 13 to 14 years increasing to 17 to 18 in Year 12. In School Year 9 in Group A and Group B schools, 16 and 9 subjects respectively had not attained menarche and these were excluded from the study. All the subjects belonged to the Sinhalese ethnic group.

Consent was obtained from school principals concerned and informed consent from the parents of the subjects who took part in the study. Ethical approval was obtained from the Ethical Review Committee of the Faculty of Medicine, University of Peradeniya.

A questionnaire (first) was given to the selected subjects in the four schools. Each question was read out and explained to the class and the subjects were requested to answer all the questions independently. The questionnaire obtained information regarding the following: general details of the subject and family, position in class at the last assessment, a detailed menstrual history with special reference to abdominal pain experienced during menstruation, average number of sanitary towels or pads used per cycle, duration of bleeding, inability to carry out normal daily work and regular absenteeism from school or classes due to the pain and traditions regarding menstruation. The pain, if any, was marked on a linear analogue scale graded from ' 0 ' at one end indicating 'no pain' to ' 10 ' at the other end indicating 'severe pain' (6).

An educational programme was conducted to subjects of Groups A1 and B1 (study groups) by the researcher immediately after they completed the questionnaire. The programme consisted of a lecture given in simple language with the use of pictures projected on a screen. The aims of the programme were to make them aware of the following: the physiology of the normal menstrual cycle and reproductive function; importance of regular physical activity; general aspects like nutrition, hygiene, bowel habits, etc. and simple ways of overcoming any pain or discomfort experienced during menstruation. Questions and free discussion were encouraged at the end of the lecture. Groups A2 and B2 were treated as the control groups.

A second questionnaire was given to the same classes as before in all four schools six months later. This obtained the following information with regard to the last 2 menstrual cycles: degree of pain indicated on a linear analogue scale, duration of disability and absenteeism from school or classes due to the disability. More than $75 \%$ of the first sample from each school were available to answer the second questionnaire. 
The first questionnaire was analysed by Group and by School Year with regard to degree of pain, duration of disability, prevalence of pain and disability and absenteeism from school or classes. The degree of pain was correlated with the position in class, number of sanitary pads used per cycle, duration of menstruation, cycle length and age at menarche, considering all subjects as one group. The traditions with regard to menstruation were also analysed as one group. The second questionnaire was analysed by Groups similar to the first questionnaire.

\section{Results}

Student's $t$ test was used to find the significance of difference between means and the $z$ test to find that between percentages.

\section{Analysis of the first questionnaire}

\section{Social class}

The subjects were classified into social classes using the father's occupation, according to the British classification (11). A significantly higher percentage $(p<0.001)$ of subjects in Group A $(89 \%)$ belonged to social classes 1 to 3 compared to Group B (22\%).

\section{Analysis by Group}

The percentage of girls with pain or with disability was not significantly different $(p>0.05)$ between Groups $A 1$ and $A 2, B 1$ and $B 2$ or $A$ and $B$. However, the percentage absent from school or classes was significantly higher $(p<0.001)$ in Groups B1, B2 and B when compared to A1, A2 and A respectively (Table 1).

The degree of pain and the duration of disability were not significantly different $(p>0.05)$ between Groups A1 and A2, B1 and B2 or A and B (Table 2).

\section{Analysis by School Year}

Groups A and B were analysed together by School Year.

The percentage of girls suffering from pain or disability and the percentage of absenteeism showed an upward trend from Year 9 with a significant increase $(p<0.001)$ from Year 10 to 11 (Table 3).
Table 1

The percentage of girls with pain, disability and absenteeism analysed by Group

(first questionnaire)

\begin{tabular}{ccccc}
\hline $\begin{array}{c}\text { Group } \\
(\mathrm{N})\end{array}$ & Pain & Disability & $\begin{array}{c}\text { Absent } \\
\text { school }\end{array}$ & $\begin{array}{c}\text { Absent } \\
\text { classes }\end{array}$ \\
\hline A1 (155) & 73 & 60 & 14 & 15 \\
A2 (190) & 75 & 62 & 15 & 16 \\
B1 (110) & 73 & 57 & 35 & 31 \\
B2 (87) & 74 & 64 & 32 & 24 \\
A (345) & 74 & 61 & 14 & 15 \\
B (197) & 71 & 59 & $34^{2}$ & $27^{4}$ \\
\hline
\end{tabular}

$\mathrm{N}=$ Number of subjects

" $\mathrm{p}<0.001$ vs preceding group

Table 2

Degree of pain and duration of disability analysed by Group

(first questionnaire)

\begin{tabular}{crcrc}
\hline Group & $\mathrm{N}$ & $\begin{array}{c}\text { Degree of } \\
\text { pain } \\
\text { mean (SD) }\end{array}$ & $\mathrm{N}$ & $\begin{array}{c}\text { Disability } \\
\text { hours } \\
\text { mean (SD) }\end{array}$ \\
\hline A1 & 113 & $5.60(2.8)$ & 93 & $4.04(4.3)$ \\
A2 & 142 & $5.69(2.6)$ & 118 & $3.14(3.0)$ \\
B1 & 80 & $5.14(2.5)$ & 63 & $2.92(3.8)$ \\
B2 & 64 & $5.73(2.7)$ & 56 & $3.99(4.3)$ \\
A & 255 & $5.66(2.6)$ & 210 & $3.70(3.9)$ \\
B & 140 & $5.41(2.6)$ & 116 & $3.40(4.1)$ \\
\hline
\end{tabular}

$\mathbf{N}=$ Number of subjects

All differences are not significant

The degree of pain showed an upward trend from Year 9 with a significant increase $(p<0.001)$ occurring from Year 11 to 12 (Table 4). 
Table 3

The percentage of girls with pain, disability and absenteeism analysed by School Year

(first questionnaire)

\begin{tabular}{rrrrr}
\hline $\begin{array}{c}\text { School } \\
\text { Year (N) }\end{array}$ & Pain & Disability & $\begin{array}{c}\text { Absent } \\
\text { school }\end{array}$ & $\begin{array}{c}\text { Absent } \\
\text { classes }\end{array}$ \\
\hline $9(94)$ & 64 & 55 & 15 & 7 \\
$10(129)$ & 64 & 49 & 16 & 12 \\
$11(129)$ & $76^{\star}$ & $67^{\star}$ & $29^{\star}$ & $27^{\star}$ \\
$12(190)$ & 78 & 71 & 22 & 22 \\
\hline
\end{tabular}

$\mathrm{N}=$ Number of subjects

${ }^{\mathrm{p}} \mathrm{p}<0.001$ vs preceding group

Table 4

Degree of pain and duration of disability analysed by School Year

(first questionnaire)

\begin{tabular}{rrrrrr}
\hline $\begin{array}{c}\text { School } \\
\text { Year }\end{array}$ & $\mathrm{N}$ & $\begin{array}{c}\text { Degree of } \\
\text { pain } \\
\text { mean (SD) }\end{array}$ & $\mathrm{N}$ & $\begin{array}{c}\text { Disability } \\
\text { hours } \\
\text { mean (SD) }\end{array}$ \\
\hline 9 & 60 & 4.66 & $(2.1)$ & 52 & $3.5(2.6)$ \\
10 & 83 & 5.00 & $(2.7)$ & 63 & $4.4(3.6)$ \\
11 & 98 & 4.90 & $(2.3)$ & 86 & $3.7(2.9)$ \\
12 & 148 & 6.20 & $(2.7)^{\circ}$ & 135 & $5.3(4.2)^{\circ}$ \\
\hline
\end{tabular}

$\mathrm{N}=$ Number of subjects

' $p<0.001$ vs preceding group

Correlation of the degree of pain with biological factors and academic performance

The degree of pain correlated significantly $(r=0.21, p<0.05)$ with the duration of disability, but did not correlate significantly $(r=0.02$ to 0.1 , $p>0.05$ ) with age at menarche, length of the cycle, number of sanitary pads used per cycle, duration of menstruation or position in class.

\section{Analysis of traditions}

The common traditions resorted to during menstruation were found to be abstinence from bathing and eating oily food. There was no significant difference ( $p>0.05$ ) between the percentage of girls who abstained from eating oily food in Group A (21\%) and Group B (24\%). The percentage who abstained from bathing and from both bathing and eating oily food during menstrual periods were significantly lower ( $p<0.05$ and $p<0.001$ respectively) in Group $A$ ( $4 \%$ and $7 \%$ respectively) when compared to Group B ( $9 \%$ and $20 \%$ respectively).

\section{Analysis of the second questionnaire}

The percentage of girls with pain or with disability was not significantly different $(p>0.05)$ between Groups A1 and A2, B1 and B2 or A and $B$ as in the case of the first study. However, percentage of absenteeism from school or classes was significantly lower $(p<0.05)$ in Groups $A 1$ and B1 when compared with Groups A2 and B2 respectively unlike in the first study. Percentage of absenteeism in Group B from school or classes was still significantly higher $(p<0.001)$ than in Group A as in the first study (Table 5).

When the results of the second questionnaire were compared with those of the first, the percentage of girls with pain and disability were not significantly different ( $p>0.05$ ) from the first study in any Group. However, both Groups A1 and $B 1$ had significantly lower $(p<0.001)$ absenteeism rates on the second occasion, thus reducing the prevalence of absenteeism in both Groups A and B significantly $(p<0.05)$ on the second occasion.

The degree of pain and duration of disability were not significantly different $(p>0.05)$ betw'een Groups $A 1$ and $A 2, B 1$ and $B 2$ or $A$ and $B$ as in the first study (Table 6).

These variables were not significantly different $(p>0.05)$ from those in the first study in any Group. 
Table 5

The percentage of girls with pain, disability and absenteeism analysed by Group

(second questionnaire)

\begin{tabular}{cccc}
\hline $\begin{array}{c}\text { Group } \\
(\mathrm{N})\end{array}$ & Pain Disability & $\begin{array}{l}\text { Absent } \\
\text { school }\end{array}$ & $\begin{array}{c}\text { Absent } \\
\text { classes }\end{array}$
\end{tabular}

\begin{tabular}{rrrrr}
\hline A1 (147) & 70 & 56 & 3 & 3 \\
A2 (189) & 72 & 62 & $14^{*}$ & $12^{\circ}$ \\
B1 $\quad(91)$ & 64 & 62 & 15 & 15 \\
B2 $\quad(73)$ & 66 & 62 & $30^{\circ}$ & $22^{\circ}$ \\
A (336) & 71 & 59 & 9 & 8 \\
B (164) & 65 & 62 & $21^{\circ}$ & $18^{\circ}$ \\
\hline
\end{tabular}

$\mathrm{N}=$ Number of subjects

$\mathrm{p}<0.001, \mathrm{~b}<0.05 \mathrm{vs}$ preceding group

\section{Table 6}

Degree of pain and duration of disability analysed by Group

(second questionnaire)

\begin{tabular}{crcrc}
\hline Group & $\mathrm{N}$ & $\begin{array}{c}\text { Degree of } \\
\text { pain } \\
\text { mean (SD) }\end{array}$ & $\mathrm{N}$ & $\begin{array}{c}\text { Disability } \\
\text { hours } \\
\text { mean (SD) }\end{array}$ \\
\hline A1 & 103 & $5.11(2.1)$ & 82 & $4.17(4.0)$ \\
A2 & 136 & $5.56(2.5)$ & 117 & $3.54(2.9)$ \\
B1 & 58 & $5.79(1.9)$ & 56 & $3.68(4.3)$ \\
B2 & 48 & $5.94(2.2)$ & 45 & $3.44(3.9)$ \\
A & 239 & $5.36(2.3)$ & 199 & $4.46(4.5)$ \\
B & 106 & $5.84(2.2)$ &. .101 & $.3 .54(4.0)$ \\
\hline N
\end{tabular}

$\mathrm{N}=$ Number of subjects

All differences are not significant

Discussion

The 2 groups of subjects studied were different in that Group A subjects attended girls' schools and a significantly higher percentage belonged to higher social classes. But it is reasonable to assume that the subjects in the four schools were similar with regard to the degree of pain and duration of disability, eventhough the assessment was not purely objective. The prevalence of pain and disability were also not significantly different between Groups A and B. However, regular absenteeism specifically due to dysmenorrhoea was significantly higher in Group B Schools, where the majority belonged to lower social classes and studied in coeducational schools.

The increase in the prevalence of dysmenorrhoea with increasing age in this age group conform to earlier studies (6) and supports the observation that anovulatory cycles which occur in the first year or so after menarche are not accompanied by dysmenorrhoea (5). The higher absenteeism rate with increasing age may be explained on this basis. In Sri Lanka, traditional beliefs regarding menstruation as described by Jeffcoate are still prevalent even among the educated (8). The percentage of girls who resorted to such traditions was higher, and significantly so in some cases in Group B, possibly due to the influence of mothers from lower social classes having a lower level of education. This may be one factor leading to a higher absenteeism rate in co-educational schools inspite of the subjects having a similar degree of pain and disability as the subjects in girls' schools. Other more obvious reasons that have to be considered are the fear of staining the white school uniform and getting into embarrassing situations in front of males and drawbacks caused by .restricted toilet facilities. Our results indicate that social class and co-education may affect school attendance during menstruation.

The study groups were exposed to an educational programme on the significance of menstruation and dealing with associated problems especially the pain. Six months later, neither the study groups nor the control groups showed any significant change in the degree of pain or disability and the prevalence of pain or disability. However, the study groups showed a significant decrease in the prevalence of absenteeism. An understanding of the 
significance of menstruation may have been responsible for the improvement in school attendance.

The prevalence, degree of pain and duration of disability in both Groups A and B are not significantly different $(p>0.05$ ) from those of first year medical students as reported by us earlier (10). More than $80 \%$ of those who had any degree of pain complained of inability to carry out normal daily work for a variable period in both studies.

The prevalence of dysmenorrhoea is similar to that reported for Swedish girls, while the degree of pain is higher. The low correlation of the degree of pain with age at menarche, duration of menstruation and the degree of bleeding are not in conformity with the results of this study (5). Academic performance did not show a correlation with the degree of pain supporting Fontana's findings (7).

It is still not recognised among the general population that dysmenorrhoea is a biologic disorder. Earlier studies have shown that education and self-help measures may be valuable in reducing the disability (4). The results of the present study support the view that education helps to improve poor school attendance due to problems associated with dysmenorrhoea. Exposure to educational programmes early in their reproductive life will be beneficial to young girls in coping with such problems even later on in life.

\section{Acknowledgments}

This work was supported by a grant from the Health Sciences Research Programme. The author wishes to thank Mercy Bandara and Mala Sumanaratne of the Department of Physiology for assistance in collection and analysis of data.

\section{References}

1. Novak E R, Jones G S, Jones $H$ W. Dysmenorrhoea, premenstrual tension and related disorders. In: Novak's textbook of gynaecology, 9th Ed. Baltimore: Williams and Wilkins Co. 1975. P 720-730.
2. Ylikorkala O, Dawood M Y. New concepts in dysmenorrhoea. American Journal of Obstetrics and Gynaecology 1978; 130 : 833-847.

3. Robinson J C, Plichta S, Weisman C S, Nathanson $C$ A, Ensminger $M$. Dysmenorrhoea and use of oral contraceptives in adolescent women attending a family planning clinic. American Journal of Obstetrics and Gynaecology 1992; 166:578-583.

4. Wilson C A, Keye W R. A survey of adolescent dysmenorrhoea and premenstrual symptom frequency. Journal of Adolescent Health Care 1989; 10:317-322.

5. Andersch B, Milsom I. An Epidemiologic study of young women with dysmenorrhoea. American Journal of Obstetrics and Gynaecology 1982; 144: 655-660.

6. Klein J, Litt I F. Epidemiology of adolescent dysmenorrhoea. Paediatrics 1981; 68: 661-664.

7. Fontana D, Rees V. Primary dysmenorrhoea, educational performance and cognitive and affective variables in adolescent school girls. British Journal of Educational Psychology 1982; 52:199-204.

8. Jeffcoate N. Dysmenorrhoea. In: Principles of Gynaecology, 4th Ed. London: Butterworth and Co. Ltd. 1975. P 537-546.

9. Karunadasa C. Kanthawan Kere Bahulawa Pazvathina Roga. In: Sthri Roga. Ayurvedaya Sarala Basin Grantha Malawa No. 9. 1984. P 19-36.

10. Balasuriya P. Dysmenorrhoea in medical students, Proceedings of the Second International Medical Congress, Kandy, Sri Lanka. 1994. P 99-100.

11. Barker D J P, Hall A J. Practical Epidemiology, 4th Ed. Longman Group UK Ltd., 1991; 65-66. 